\title{
Neutral organic redox pairs based on sterically hindered hydroquinone/ benzoquinone derivatives for dye-sensitized solar cells
}

\author{
Natalie Flores-Díaz $^{\mathrm{a}, \mathrm{b}}$, Andrea Soto-Navarro ${ }^{\mathrm{a}}$, Marina Freitag ${ }^{\mathrm{d}}$, Guy Lamoureux $^{\mathrm{b}, \mathrm{c}, *}$, \\ Leslie W. Pineda ${ }^{\mathrm{a}, \mathrm{b}, *}$ \\ ${ }^{a}$ Centro de Electroquímica y Energía Química (CELEQ), Universidad de Costa Rica, 2060 San José, Costa Rica \\ ${ }^{\mathrm{b}}$ Escuela de Química, Universidad de Costa Rica, 2060 San José, Costa Rica \\ c Centro de Investigación en Productos Naturales (CIPRONA), Universidad de Costa Rica, 2060 San José, Costa Rica \\ d Department of Chemistry, Ångström Laboratory, Uppsala University, 75126 Uppsala, Sweden
}

\section{A R T I C L E I N F O}

\section{Keywords:}

Dye-sensitized solar cells

Liquid electrolyte

Organic redox pair

Hydroquinone

Benzoquinone

\begin{abstract}
A B S T R A C T
Substituted derivatives of hydroquinone/benzoquinone were studied as organic redox mediators in the electrolyte for dye-sensitized solar cells (DSSCs). Thus, di-tert-butylhydroquinone (DTHQ), thymohydroquinone (ThymHQ) and phenylhydroquinone (PhHQ), were combined with their oxidized counterparts to form the pairs DTHQ/DTBQ, ThymHQ/ThymBQ, and PhHQ/PhBQ. In general, the characteristic parameters of the DSSCs with the substituted derivatives surpassed those of the DSSC with the unsubstituted hydroquinone/benzoquinone electrolyte. The short-circuit current $\left(\mathrm{J}_{\mathrm{SC}}\right)$ of the devices using DTHQ/DTBQ and ThymHQ/ThymBQ (13.61 $\mathrm{mA} \mathrm{cm}^{-2}$ and $12.56 \mathrm{~mA} \mathrm{~cm}^{-2}$, respectively) are comparable to the $\mathrm{J}_{\mathrm{SC}}$ obtained for cobalt(II/III) tris (bipyridine) as a reference electrolyte $\left(14.54 \mathrm{~mA} \mathrm{~cm}^{-2}\right)$. However, parameters such as open-circuit voltage $\left(\mathrm{V}_{\mathrm{OC}}\right)$ and fill factor (FF) (547 $\mathrm{mV}$ and 0.48 , respectively) are far from competitive. The best photovoltaic performance was obtained for the pair ThymHQ/ThymBQ using a triphenylamine (TPA)-based organic dye (LEG4) as sensitizer and a hybrid counter electrode with poly(3,4-ethylenedioxythiophene) (PEDOT) and graphene. These experimental conditions give under 1 sun $(98 \%)$ the highest efficiency ( $\eta=3.19 \%)$; low-light intensities of $12.3 \%$ and $51.8 \%$ suns lead to efficiencies of $3.34 \%$ and $3.29 \%$, respectively. Electrochemical impedance spectroscopy (EIS) revealed that the main cause for loss in photocurrent is the low recombination resistance compared to Co(II/III) as reference electrolyte. Based on the EIS analysis, a down-shift of the conduction band of $\mathrm{TiO}_{2}$ was found for all assembled devices containing the organic redox mediators, which explains the low $\mathrm{V}_{\mathrm{OC}}$ values for these derivatives.
\end{abstract}

\section{Introduction}

Dye-sensitized solar cells (DSSCs) are third generation solar cells that can be produced in a variety of colors and shapes and can work under diffuse light conditions (O'Reagan and Grätzel, 1991; Zhang et al., 2016). They are comprised of a photoanode - typically a transparent conductive glass substrate of fluorine-doped tin oxide $\left(\mathrm{SnO}_{2}: \mathrm{F}\right.$, FTO) - a thin layer of a nanostructured semiconductor (e.g., $\mathrm{TiO}_{2}$ ), which is then sensitized with dye molecules, and a counter electrode (CE) with a thin layer of a catalyst such as platinum (Pt) or poly $(3,4-$ ethylenedioxythiophene) (PEDOT) (Kalyanasundaram et al., 2010). Importantly, as dye molecules excite upon photon absorption followed by electron injection, the oxidized state of the dye is reduced to its ground state by an electron transfer from a redox couple in a liquid electrolyte filled between the electrodes. Together, these components contribute to the overall performance of the cell; the redox couple in the liquid electrolyte plays an important role to attain high energy conversion efficiencies (Feldt et al., 2010; Wu et al., 2016).

The redox couple $I^{-} / I_{3}^{-}$is widely used because it presents large recombination resistance and provides high electron lifetimes (Ito et al., 2005; Teuscher et al., 2014). Nonetheless, this redox couple has several disadvantages such as corrosiveness, absorption of light in the visible range, sublimation, and a large potential drop due to the mismatch of the redox potential of $I^{-} / I_{3}^{-}$compared to the highest occupied molecular orbital (HOMO) level of the sensitizer dye (Sun et al., 2015; Yum et al., 2012). In the pursuit of alternative redox shuttles, cobalt complexes such as $\left[\mathrm{Co}(\mathrm{bpy})_{3}\right]^{2+/ 3+}$ (where bpy $=2,2^{\prime}$-bipyridine) have shown a rather good match of the redox potential with the HOMO of the dye. Cobalt complexes require a lower driving force for dye regeneration, leading to higher open circuit voltages $\left(\mathrm{V}_{\mathrm{OC}}\right)$, favorable

\footnotetext{
* Corresponding authors at: Escuela de Química, Universidad de Costa Rica, 2060 San José, Costa Rica.

E-mail address: leslie.pineda@ucr.ac.cr (L.W. Pineda).
} 
power conversion efficiencies ( $\eta$ ), and other characteristic parameters (e.g., short circuit current density, $\mathrm{J}_{\mathrm{SC}}$, and fill factor, FF) (Safdari et al., 2016; Bella et al., 2016). However, the large size of such coordination complexes decreases the diffusion coefficient of the active species in the electrolyte, the rate of dye regeneration, and the efficiency of the cell. Another unwanted issue with these colored complexes relates, in some cases, with the absorption of light in the visible range competing with the dye (Aghazada et al., 2016). This issue can be solved by optimization of organic redox couples, as shown with the use of disulfide/ thiolate redox couples, which exhibit low absorption in the visible range (Wang et al., 2010). Alternatively, some interesting outcomes regarding iodine/iodide redox mediators in DSSCs made use of a hydrogel electrolyte consisting of carboxymethylcellulose and $I^{-} / I_{3}^{-}$in an aqueous systems (Bella et al., 2017), or membrane-based separators (Nair et al., 2015; Shanti et al., 2016).

On the other hand, the organic redox pair hydroquinone/benzoquinone (HQ/BQ) has spurred a great body of research due to its importance in biological processes (Alligrant et al., 2010). Interestingly, the electron transfer of the redox couple is a thermodynamically reversible process (Shaidarova et al., 2003). In non-aqueous media and in the absence of proton donor/acceptors, the hydroquinone dianion undergoes two successive one-electron steps (Fig. 1a). In the presence of proton donor/acceptors, the electron transfer process is coupled with the proton transfer processes (Fig. 1b) (Guin et al., 2011).

Previous experiments have shown that quinones and their electron transfer processes are coupled with proton transfer processes of the corresponding hydroquinones, in the absence or presence of proton donors or acceptors (Bhat, 2012). When there are proton acceptors in the media, the mechanism starts with the deprotonation of the hydroquinone $\left(\mathrm{QH}_{2}\right)$ compound, then an oxidation step forms the radical $Q H$ ', which is further deprotonated leading to the radical anion $Q^{\cdot}{ }^{-}$that, upon oxidation, yields a quinone (Q) (Fig. S5 in Supporting Info). The overall reaction proceeds as depicted in Fig. 1b, with a two-electron/ two-proton process between the neutral hydroquinone and benzoquinone, suggesting that $\mathrm{HQ} / \mathrm{BQ}$-like redox pairs in their neutral forms can undergo electron transfer steps and could regenerate the dye in DSSC.

When hydroquinone is treated with tetramethylammonium hydroxide (TMAOH), it gives the bis-tetramethylammonium hydroquinone dianion (TMAHQ) ionic species, shown in Fig. 1a. In previous reports, the anionic hydroquinone species (TMAHQ/BQ) was used as a redox mediator in DSSCs with dye N719 as sensitizer and Pt as CE; these systems showed promising photovoltaic characteristics: $\mathrm{V}_{\mathrm{OC}}=750 \mathrm{mV}$, $\mathrm{J}_{\mathrm{SC}}=17.2 \mathrm{~mA} \mathrm{~cm}^{-2}, \mathrm{FF}=0.663$, and $8.4 \%$ conversion efficiency. With the same redox mediator, but with PEDOT as CE and the organic dye CM-309, the following parameters were achieved: $\mathrm{V}_{\mathrm{OC}}=755 \mathrm{mV}$, $\mathrm{J}_{\mathrm{SC}}=12.10 \mathrm{~mA} \mathrm{~cm}^{-2}$, FF 0.678, and $\eta=6.2 \%$ (Cheng et al., 2012, 2013).

One drawback of using TMAHQ in organic redox mediators is the limitation of the lifetime of the solar cell (Yu et al., 2013). Deprotonated hydroquinones are prone to decomposition in open air conditions, which compromises the overall performance of the DSSC.

Independently and innovatively, we examine the photovoltaic performance of a series of DSSCs using neutral HQ derivatives bearing various bulky substituents on the aromatic ring. Our molecular design provides neutral, stable organic redox shuttles. The HQ derivatives, and the corresponding BQ pair, are stable in air. Our approach also simplifies the chemical composition of the electrolyte by decreasing the number of charged species in the liquid phase. To this end, the derivatives 2,5-di-tert-butylhydroquinone, phenylhydroquinone and 2-isopropyl-5-methylhydroquinone (thymohydroquinone) are paired with their benzoquinone counterparts to render the redox pairs DTHQ/ DTBQ, PhHQ/PhBQ and ThymHQ/ThymBQ, respectively (Fig. 2). In solution, these redox pairs were optically characterized by UV-Vis spectroscopy and by cyclic voltammetry, followed by determination of their photovoltaic parameters (for instance, $\mathrm{J}_{\mathrm{SC}}, \mathrm{V}_{\mathrm{OC}}, \mathrm{FF}$, and $\eta$ ) from current density-voltage plots once the DSSC were assembled. Likewise, a series of internal processes of the assembled DSSCs were determined by electrochemical impedance spectroscopy (EIS).

\section{Experimental}

Details of the synthesis and characterization of the derivatives are described in the Supporting Information.

\subsection{Materials}

All chemicals were purchased from Sigma-Aldrich unless otherwise noted. The organic dyes $3-\left\{6-\left\{4-\left[b i s\left(2^{\prime}, 4^{\prime}\right.\right.\right.\right.$-dibutyloxybiphenyl-4-yl) amino-]phenyl\}-4,4-dihexyl-cyclopenta-[2,1-b:3,4-b']dithiophene-2yl $\}$-2-cyanoacrylic acid, LEG4, and $3-\left\{6-\left\{4-\left[\operatorname{bis}\left(2^{\prime}, 4^{\prime}\right.\right.\right.\right.$-dihexyloxybiphenyl-4-yl)amino-]phenyl\}-4,4-dihexyl-cyclopenta-[2,1-b:3,4-b'] dithiphene-2-yl\}-2-cyanoacrylic acid, Y123, were purchased from Dyenamo AB (Stockholm, Sweden).

\subsection{Solar cell preparation}

Glass substrates with fluorine-doped tin oxide (FTO, Pilkington, TEC15) were cleaned in an ultrasonic bath for $1 \mathrm{~h}$ in the following order of solvents: water, ethanol, and acetone. The FTO substrates were pretreated by immersion for $30 \mathrm{~min}$ in a $40 \mathrm{mM}$ aqueous $\mathrm{TiCl}_{4}$ solution at $70^{\circ} \mathrm{C}$, and then washed with water, to form a thin blocking layer. Mesoporous $\mathrm{TiO}_{2}$ films of $0.25 \mathrm{~cm}^{2}$ were prepared as follows: a transparent active layer was made with colloidal $\mathrm{TiO}_{2}$ paste (Dyesol DSL 30 NRD-T) by screen-printing technique and dried at $120^{\circ} \mathrm{C}$ for $6 \mathrm{~min}$ between each layer of $\mathrm{TiO}_{2}$ applied. Subsequently, a light-scattering layer (Dyesol WER2-0) was deposited on top by screen-printing. The substrates were then gradually heated in an air atmosphere oven (Nabertherm controller P320), applying a four-level program: $125^{\circ} \mathrm{C}$ (10 min), $250^{\circ} \mathrm{C}(10 \mathrm{~min}), 350^{\circ} \mathrm{C}(10 \mathrm{~min})$, and $450^{\circ} \mathrm{C}(30 \mathrm{~min})$. After sintering, the electrodes were treated in aqueous titanium tetrachloride $\left(\mathrm{TiCl}_{4}\right)$ at $70^{\circ} \mathrm{C}$ for $30 \mathrm{~min}$, then washed with water and ethanol. The thicknesses of the $\mathrm{TiO}_{2}$ films were measured with a profilometer (Veeco Dektak 3); the thicknesses are $6 \mu \mathrm{m}$ and $2 \mu \mathrm{m}$ for transparent and scattering layers, respectively. A final heating step at $500{ }^{\circ} \mathrm{C}(30 \mathrm{~min})$

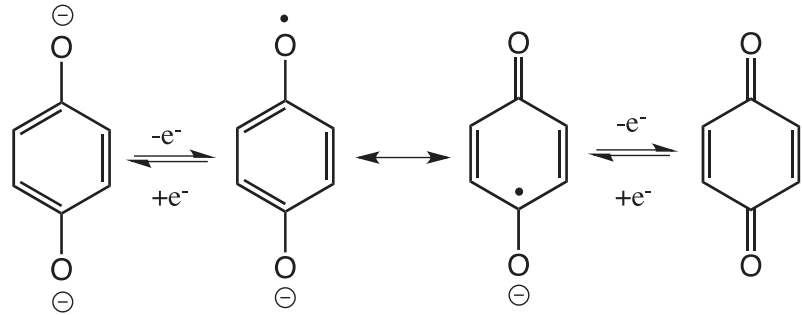

(a)

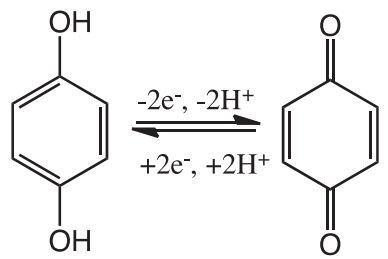

(b)

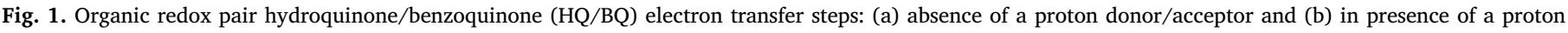
donor/acceptor. 
<smiles>CC(C)(C)C1=CC(=O)C(C(C)(C)C)=CC1=O</smiles>

(a)<smiles>CCc1ccccc1-c1cc(O)ccc1O</smiles>

(b)<smiles>CC1=CC(=O)C(C(C)C)=CC1=O</smiles>

(c)

Fig. 2. Organic redox pairs based on derivatives of the pair hydroquinone/benzoquinone, (a) DTHQ/DTBQ, (b) PhHQ/PhBQ, (c) ThymHQ/ThymBQ.

was performed followed by overnight immersion of the electrodes in the dye bath solution. The dye bath composition was 0.2 mM LEG4 in tert-butyl alcohol and acetonitrile (1:1), and for Y123 the concentration was $0.2 \mathrm{mM}$ in THF/EtOH (1:4). Then, after immersion, all films were rinsed in acetonitrile to remove the excess of dye. Solar cells were assembled using a $25 \mu \mathrm{m}$ thick thermoplastic Surlyn frame as sealant and spacer between electrodes, with a (PEDOT)-coated counter electrode (TEC8). The PEDOT electrodes were prepared by electro-polymerization of 3,4-ethylenedioxythiophene (EDOT) from a micellar aqueous solution of $0.1 \mathrm{M}$ sodium dodecyl sulfate (SDS) and 0.01 M EDOT. The electrolyte solution was introduced under vacuum through a hole predrilled in the counter electrode and sealed with thermoplastic Surlyn and a glass coverslip. The electrolyte composition was $0.2 \mathrm{M}$ of the HQ derivative and $0.04 \mathrm{M}$ of the corresponding benzoquinone derivative, $0.1 \mathrm{M}$ lithium bis(trifluoromethanesulfonyl)imide (LiTFSI), and $0.5 \mathrm{M}$ 4-tert-butylpyridine (TBP) in acetonitrile. Reference electrolytes were prepared for comparison, by using $0.22 \mathrm{M} \mathrm{Co}(\mathrm{bpy})_{3}\left(\mathrm{PF}_{6}\right)_{2}$, and $0.05 \mathrm{M}$ $\mathrm{Co}(\mathrm{bpy})_{3}\left(\mathrm{PF}_{6}\right)_{3}$, with the same additives and solvent used in the case of the organic pairs.

\subsection{Electrochemical measurements}

Cyclic voltammetry (CV) measurements were performed with a Potentiostat/Galvanostat PGSTAT 128N Metrohm/Autolab with a three-electrode setup cell. A glassy carbon electrode as the working electrode, a graphite rod as the counter electrode, and a non-aqueous reference electrode of $\mathrm{Ag} / \mathrm{AgCl}$ ( $2 \mathrm{M}$ in ethanol) were used. The electrolyte solutions contained $2 \mathrm{mM}$ of the hydroquinone derivative, $0.1 \mathrm{mM}$ of the corresponding benzoquinone, and $0.1 \mathrm{M}$ of $\mathrm{LiClO}_{4}$ as supporting electrolyte in dry acetonitrile. The scan rate was $100 \mathrm{mV} \mathrm{s}^{-1}$, formal potentials were determined versus ferrocenium/ ferrocene as a reference system, and then versus normal hydrogen electrode (NHE) with a value established for $\mathrm{Fc}^{+} / \mathrm{Fc}=0.64 \mathrm{~V}$ versus NHE in acetonitrile and $25^{\circ} \mathrm{C}$ (Pavlishchuk and Addison, 2000).

\subsection{Solar cell characterization}

Current-voltage (I-V) characteristic curves and photocurrent-dynamics were measured using a Xenon lamp of $450 \mathrm{~W}$ (Oriel USA) as light source, with a filter Schott K113 Tempax and matched to AM 1.5G solar standard conditions using a reference Si photodiode. The current and voltage were measured and controlled by a Keithley 2400 digital source meter (Keithley, USA) and the current measurement was set up to be delayed $80 \mathrm{~ms}$ from applying voltage. A set of metal mesh filters was used to adjust the light intensity to a desired level. A black metal mask with a $0.16 \mathrm{~cm}^{2}$ aperture was used to define the active area.

\subsection{Electrochemical impedance spectroscopy (EIS)}

Analysis of DSSC with the respective organic pairs as mediators in the electrolyte was measured in dark conditions using a SP-300 bipotentiostat (Biologic Science Instrument). A range of potentials was selected, 18 steps linearly spaced between 0 and $1.0 \mathrm{~V}$, but only from $0 \mathrm{~V}$ to approximately $0.1 \mathrm{~V}$ beyond the $\mathrm{V}_{\mathrm{OC}}$ of every respective DSSC were taken in account for the simulation and data analysis. The AC amplitude voltage perturbation was $10 \mathrm{mV}$, and the range of frequencies was from $7 \mathrm{MHz}$ to $0.1 \mathrm{~Hz}$ at forward applied bias. Data analysis of the obtained impedance spectra was realized using Zview software from Scribner Associate Inc. The data was fitted into the corresponding equivalent circuit, using for the corresponding potentials the transmission line defined by DX type 11- Bisquert \#2.

\section{Results and discussion}

The hydroquinone and benzoquinone compounds under study did not decompose over several months in open air conditions, hence all the electrolytes were prepared and manipulated under normal conditions (without excluding atmospheric oxygen, water or light).

UV-Vis spectroscopy was employed to analyze the optical behavior for the electrolytes containing the organic redox pairs: HQ/BQ, PhHQ/ PhBQ, DTHQ/DTBQ, and ThymHQ/ThymBQ (Fig. 3). The formulation of the electrolytes consists of the hydroquinone derivative $(0.4 \mathrm{M})$ and the corresponding oxidized species (benzoquinone, $0.02 \mathrm{M}$ ), TBP $(0.5 \mathrm{M})$, and LiTFSI $(0.1 \mathrm{M})$ in dry acetonitrile; this composition was further used during the photovoltaic characterizations of the assembled devices. For the electrolytes with HQ, ThymHQ, and DTHQ derivatives the absorbance in the visible range is almost negligible, whereas PhHQ weakly absorbs between 400 and $500 \mathrm{~nm}$. Since the maximum absorption peak of the selected dyes LEG4 (Ellis et al., 2013) and Y123 (Tsao et al., 2011) are 541 and $530 \mathrm{~nm}$, respectively, we found that competition for light absorption of our derivatives is minimum, thus high injection rates of photogenerated electrons can be expected.

The electrochemical features for the HQ derivatives are measured using cyclic voltammetry (CV) experiments (Fig. 4). To provide the same proportion of HQ/BQ for the assembled solar devices (20:1, respectively), the chemical composition of all organic redox pairs is comprised of hydroquinone derivative $(2 \mathrm{mM})$, benzoquinone

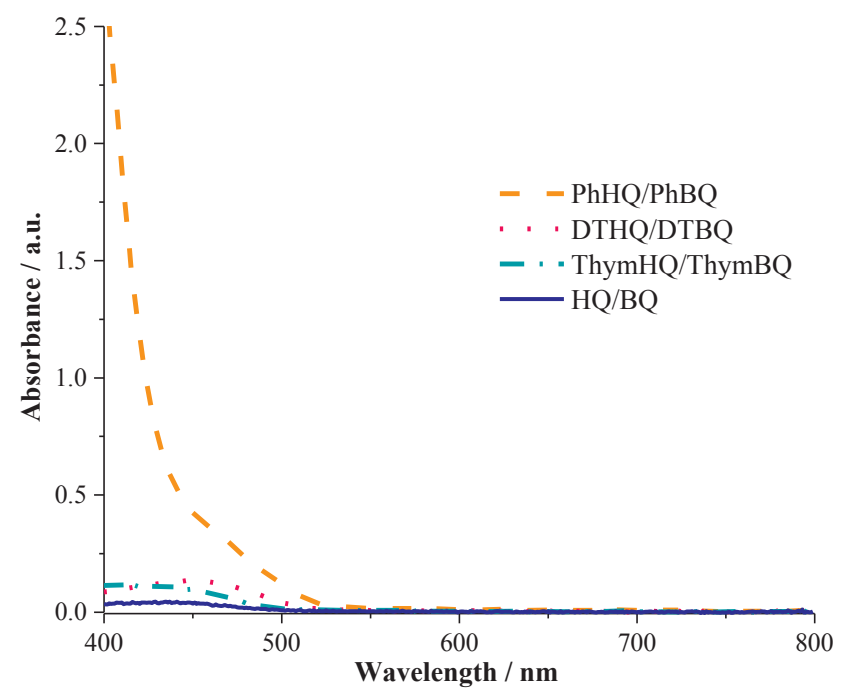

Fig. 3. Absorption spectra of the electrolytes containing the organic redox pairs with a composition of $0.4 \mathrm{M}$ of the hydroquinone derivative and $0.02 \mathrm{M}$ of the benzoquinone counterpart, $0.5 \mathrm{M}$ TBP and $0.1 \mathrm{M}$ LiTFSI. 


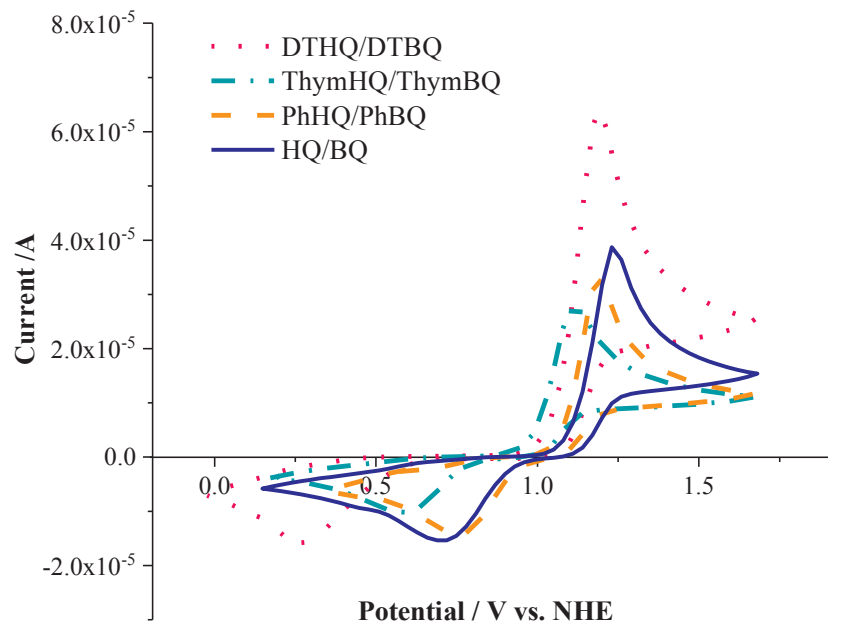

Fig. 4. Cyclic voltammograms of the different organic redox pairs with a concentration of the hydroquinone derivative of $2 \mathrm{mM}$, benzoquinone counterparts $0.1 \mathrm{mM}+\mathrm{LiClO}_{4} \mathrm{O} 0.1 \mathrm{M}$ in dry acetonitrile. A three-electrode cell with a glassy carbon electrode as the working electrode, a graphite rod as the counter electrode, and a non-aqueous reference electrode of $\mathrm{Ag} / \mathrm{AgCl}$ ( $2 \mathrm{M}$ in ethanol), and scan rate of $100 \mathrm{mV} \mathrm{s}^{-1}$.

counterpart $(0.1 \mathrm{mM})$, and $\mathrm{LiClO}_{4}(0.01 \mathrm{M})$ as supporting electrolyte in dry acetonitrile.

Previous reports disclosed that HQ in aprotic solvents undergoes facile and reversible electron transfer steps; the nature of the substituent groups affect the general trend of displacements in the reduction and oxidation peaks (Gupta and Linschitz, 1997; Uchimiya and Stone, 2009). By contrast, other electrochemical measurements (also in aprotic media) revealed two-electron irreversible oxidation steps and two-electron irreversible reduction steps for hydroquinones (GamboaValero et al., 2016). In fact, the specific mechanisms in non-aqueous media depend strongly on the presence or absence of proton donor/ acceptors.

For reversible one-electron reactions, the thermodynamic separation of the oxidation and reduction peaks (peak-to-peak separation) at $25^{\circ} \mathrm{C}$ should be approximately $59 \mathrm{mV}$ and the height of both peaks should be same (the ratio of the anodic current, $\mathrm{I}_{\mathrm{pa}}$, and the cathodic current, $I_{p c}$, equals 1 for a reversible redox process) (Girault, 2005). For hydroquinone/benzoquinone couples, two single-electron transfer steps should be expected, following the pathway as shown in Fig. 1a, or one transfer step with 2-electrons with a peak-to-peak separation of $29.5 \mathrm{mV}$, as shown in the mechanism Fig. 1b (Girault, 2005). The cyclic voltammograms of the HQ derivatives are shown in Fig. 4; they exhibit an irreversible behavior, since the peak-to-peak separation is greater than $59 \mathrm{mV}$. Such electron transfer processes are usually followed by proton transfers (Bhat, 2012), and it is possible that the first electrontransfer step and the first proton-transfer step are kinetically controlled (Astudillo et al., 2007). Furthermore, the height of the oxidation peak for all derivatives is greater than the reduction peak, which indicates a dimerization of the intermediates (Staley et al., 2014). Anionic intermediates of quinones can interact strongly by hydrogen bonding with other species (Zhu et al., 2010), forming a quinhydrone-like complex (dimer) via strong hydrogen bonds (Gamboa-Valero et al., 2016).

Interestingly, irreversible features in the cyclic voltammograms cannot be explained using the aforementioned mechanisms (see Fig. S5); however, these features can be explained by an irreversible protoncoupled electron transfer in HQ/BQ-like systems, as follows (Astudillo et al., 2007; Wang et al., 2013; Gamboa-Valero et al., 2016):

$\mathrm{QH}_{2} \rightleftharpoons \mathrm{QH}_{2}^{++}+e^{-}$

$\mathrm{QH}_{2}{ }^{+} \rightleftharpoons \mathrm{QH}^{\cdot}+\mathrm{H}^{+}$
Table 1

Electrochemical data for the hydroquinone derivatives in dry acetonitrile.

\begin{tabular}{llll}
\hline Redox pair & $\begin{array}{l}\text { Oxidation peak }(\mathrm{V}) \\
\text { NHE }\end{array}$ & $\begin{array}{l}\text { Reduction peak }(\mathrm{V}) \\
\text { NHE }\end{array}$ & $\begin{array}{l}\text { "E } 1 / 2 "(\mathrm{~V}){ }^{\mathrm{a}} \\
\mathrm{NHE}\end{array}$ \\
\hline HQ/BQ & 1.256 & 0.715 & 0.985 \\
DTHQ/DTBQ & 1.238 & 0.292 & 0.765 \\
PhHQ/PhHQ & 1.218 & 0.754 & 0.986 \\
ThymHQ/ThymHQ & 1.136 & 0.561 & 0.848
\end{tabular}

a " $E_{1 / 2}$ " represents the average or mid-value between the reduction and oxidation peaks observed in the voltammograms, but it does not indicate the reversible redox potential.

$\mathrm{QH}^{\cdot} \rightleftharpoons \mathrm{QH}^{+}+e^{+}$

$\mathrm{QH}^{*}+\mathrm{QH}^{\cdot} \rightleftharpoons \mathrm{Q}+\mathrm{QH}_{2}$

Even though the oxidation and reduction processes shown by the organic pairs are seemingly not related through the same mechanism path, they both undergo well-defined reduction and oxidation process (as seen in the voltammograms). In terms of the DSSC, the redox mediator should undergo a reduction at the counter electrode in the presence of the dye in the oxidized form, and an oxidation process to regenerate the dye molecules in their ground state. Although the experimental redox pairs do not show Nernstian reversible behavior, the well-defined and separated peaks observed in the cyclic voltammograms could represent charge transfer processes and charge regeneration in the DSSC.

In Table 1, the electrochemical parameters of the HQ derivatives obtained by the technique of $C V$ are reported. The redox potentials " $E_{1 /}$ 2 " in this case represent only a mid-value between the oxidation and reduction peaks, since the processes are not reversible. Both DTHQ/ DTBQ and ThymHQ/ThymBQ pairs exhibited oxidation and reduction peaks shifted to less positive values, which are in accordance with the expected behavior of substituted quinones, where electron-donating groups tend to lower the reduction potential. For the PhHQ/PhBQ, the reduction peak value is greater than the value for HQ/BQ, suggesting that phenyl group acts as an electron-withdrawing group (Uchimiya and Stone, 2009).

To further study the electrochemical characteristics of liquid electrolytes containing organic redox mediators based on HQ/BQ derivatives in solar-cell devices, symmetric cells were assembled with identical electrodes of PEDOT and the organic electrolytes to obtain the limiting current plots (Fig. S6 in Supporting Info), and diffusion coefficient values were measured (Table 2).

Highest values of $\mathrm{J}_{\text {lim }}$ were obtained for DTHQ and ThymHQ, resulting in higher diffusion coefficients for these redox pairs, with a maximum value of $1.62 \times 10^{-6} \mathrm{~cm}^{2} \mathrm{~s}^{-1}$ for DTHQ/DTBQ. Indeed, one would expect to obtain a better performance in the DSSC with the former mediator from $\mathrm{J}-\mathrm{V}$ curve measurements (vide infra). In the case of the obtained diffusion coefficients, they are comparable to previously reported values for HQ with PEDOT electrodes (Monge-Romero and Suárez-Herrera, 2013), iodide, and cobalt. Hence, diffusion limitations of the redox mediators in the DSSC are expected to be low (Park et al., 2014).

The open-circuit voltage of DSSCs is determined by the difference between the Fermi level of $\mathrm{TiO}_{2}$ and the redox potential of the redox

Table 2

Electrochemical parameters for the studied symmetrical cells with electrolytes containing organic mediator pairs based on hydroquinone derivatives.

\begin{tabular}{lll}
\hline Redox pair & $\mathrm{J}_{\lim }\left(\mathrm{mA} \mathrm{cm}^{-2}\right)$ & $\mathrm{D}\left(\mathrm{cm}^{2} \mathrm{~s}^{-1}\right)$ \\
\hline HQ/BQ & 7.63 & $1.235 \mathrm{E}-06$ \\
DTHQ/DTBQ & 10.03 & $1.624 \mathrm{E}-06$ \\
PhHQ/PhBQ & 8.95 & $1.450 \mathrm{E}-06$ \\
ThymHQ/ThymBQ & 9.75 & $1.579 \mathrm{E}-06$
\end{tabular}


mediator in the electrolyte. The data of mid-potentials obtained from the oxidation and reduction peaks, " $E_{1 / 2}$ ", are an estimation of the redox potentials of these separated processes (Table 1). These $\mathrm{E}_{1 / 2}$ values are greater than the $I^{-} / I_{3}^{-}$couple $(0.354 \mathrm{~V})$, and similar to $I^{-} / I_{2}{ }^{-}$. (0.937 V) (Boschloo and Hagfeldt, 2009). These findings indicate the possibility to obtain $\mathrm{V}_{\mathrm{OC}}$ values in the range of those for $I^{-} / I_{3}^{-}$ $(0.6-0.8 \mathrm{~V})$, although the actual $\mathrm{V}_{\mathrm{OC}}$ values in the solar device can deviate given that the mid-redox potential may not necessarily define the average level of the redox pair, as they are associated with separated processes of reduction and oxidation, each one featuring different pathways. Further studies will be necessary to better understand the kinetic processes.

The photovoltaic performance of DSSCs containing organic dye Y123, PEDOT as CE and electrolytes containing organic redox pairs HQ/BQ, DTHQ/DTBQ, ThymHQ/ThymBQ and PhHQ/PhBQ were measured under AM $1.5 \mathrm{G}$ simulated solar light at a light intensity of $100 \mathrm{~mW} \mathrm{~cm}^{-2}$ with a mask of $0.16 \mathrm{~cm}^{2}$ and were compared with DSSC using $\mathrm{Co}^{2+/ 3+}$ complex as a reference electrolyte. In our case, PEDOT was chosen as CE because its high activity with quinones (Park et al., 2014) and since several attempts with Pt or graphene were unsuccessful as CE. The chemical composition of the studied organic electrolytes is made up of the hydroquinone derivative $(0.4 \mathrm{M})$, benzoquinone counterpart $(0.02 \mathrm{M})$, LiTFSI $(0.1 \mathrm{M})$ and TBP $(0.5 \mathrm{M})$ in dry acetonitrile.

The current density-voltage $(\mathrm{J}-\mathrm{V})$ curves for the best performing cells for each redox mediator are displayed in Fig. 5. The photovoltage for the organic redox pairs clearly differs from the expected values based on the "redox potential" from the electrochemical analysis (see Table 1). This difference is probably due to kinetic issues regarding reduction and oxidation processes and a possible shift of the conduction band of $\mathrm{TiO}_{2}$ toward more negative values, which might account for the low $\mathrm{V}_{\mathrm{OC}}$ of such organic shuttles. In addition, the redox potentials of hydroquinones are affected by variables such as solvent polarity, presence of proton donors or acceptors, intra- and intermolecular hydrogen bonding, water content, among others (Bhat, 2012; Gamboa-Valero et al., 2016). In our case, the electrolytes contain TBP and LiTFSI as additives that could affect the redox potential of the derivatives shifting them to lower values, thus decreasing the difference between the CB of the $\mathrm{TiO}_{2}$ and lowering the $\mathrm{V}_{\mathrm{OC}}$.

As seen from $\mathrm{J}-\mathrm{V}$ curves (Fig. 5), the performance for the synthesized derivatives is better than that of $\mathrm{HQ} / \mathrm{BQ}$ redox pair, so there is probably a favorable effect in the photovoltaic results of DSSCs as different substituent groups are introduced in the hydroquinone molecule, although in the case of $\mathrm{PhHQ} / \mathrm{PhBQ}$, the effect is less. Table 3 summarizes the photovoltaic results of the electrolytes with the organic mediators. High $\mathrm{J}_{\mathrm{SC}}$ data were attained for DTHQ and ThymHQ (average values: $12.6 \mathrm{~mA} \mathrm{~cm}^{-2}$ and $10 \mathrm{~mA} \mathrm{~cm}^{-2}$, respectively)

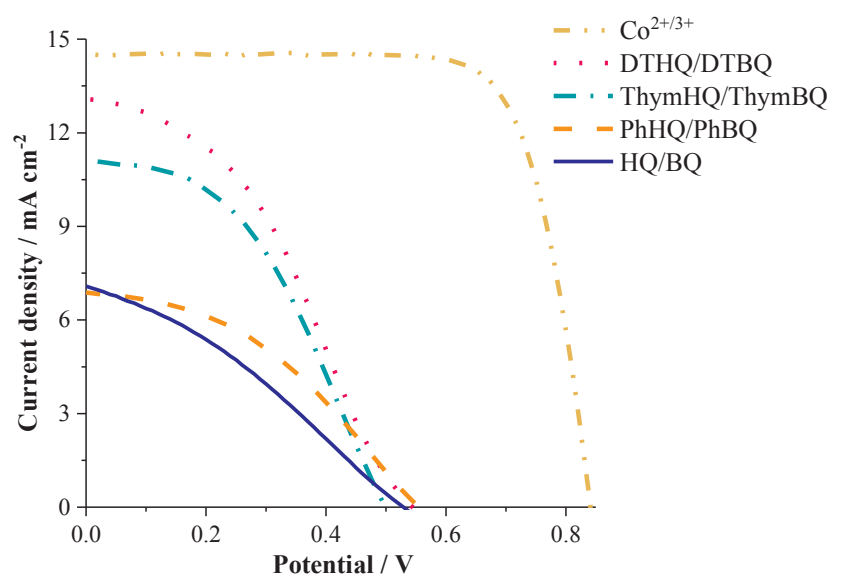

Fig. 5. J-V curves for the best performing cells of the different organic redox pairs sensitized with Y123. comparable to the best cell performance for $\mathrm{Co}^{2+/ 3+}\left(14.4 \mathrm{~mA} \mathrm{~cm}^{-2}\right)$ as electrolyte reference, with DTHQ reaching the highest conversion efficiency (2.5\%). However, low fill factors could indicate the existence of alternative paths for the electrons, decreasing the recollected amount at the photoelectrode, thus compromising the efficiency of the solar cells (Fig. 5).

To gain insight on the internal processes at DSSCs as to the effect of the different electrolytes containing the organic redox pairs in the charge transfer resistance and chemical capacitance, electrochemical impedance spectroscopy (EIS) was performed. A frequency scan from $7 \mathrm{MHz}$ to $0.1 \mathrm{~Hz}$ at room temperature in dark conditions were set for a voltage range for all samples with an alternating current (AC) amplitude of $10 \mathrm{mV}$. EIS data were fitted with the typical three channel model (Bisquert et al., 2006) using ZView software from Scribner Inc.

EIS analysis for the series resistance $\left(R_{S}\right)$ and counter electrode resistance $\left(\mathrm{R}_{\mathrm{CE}}\right)$ for all the electrolytes show low values $(6.2-8.5 \Omega$ and $3-9 \Omega$, respectively), an indication that PEDOT is suitable for the redox reaction of the quinone derivatives (Table S1 in Supporting Info).

The relation between potential and the density of states (DOS) associated with the chemical capacitance in the devices clearly show a shift of the conduction band of $\mathrm{TiO}_{2}$ toward lower values for all the organic electrolytes compared with the cobalt reference (Fig. 6).

To some extent, these measurements likely explain the low $\mathrm{V}_{\mathrm{OC}}$ values obtained for the organic couples, given that once the conduction band is lowered, the $\mathrm{V}_{\mathrm{OC}}$ values defined by this level will be then diminished. Again, some interactions of these derivatives with all the components in the electrolyte (additives and solvent) could decrease the "mid-potential", which further decrease the $\mathrm{V}_{\mathrm{OC}}$.

To compare the hydroquinone derivatives with the cobalt reference shuttle under the same electron occupation, taking into consideration the downward shift in the conduction band of DSSCs with the organic electrolytes, EIS measurements were carried out to set recombination resistance and transport resistance as a function of DOS (Fig. 7).

The recombination resistance $\left(R_{r}\right)$ for all the organic mediators is lower relative to $\mathrm{Co}^{2+/ 3+}$ electrolyte by about two orders of magnitude. These findings account for the loss in photocurrent observed in the sharp slope when going through high potentials extended to $\mathrm{V}_{\mathrm{OC}}$ in the J-V curve (associated with low FF values). Therefore, the electrons injected from the lowest unoccupied molecular orbital (LUMO) of the dye into the conduction band (CB) of $\mathrm{TiO}_{2}$ easily recombine with the organic redox mediators decreasing the rate of the injected electrons out of the circuit, subsequently affecting FF and decreasing the conversion efficiency of DSSCs.

In this context, it has been previously reported that 1,4-benzoquinones can adsorb onto the surface of CdSe nanoparticles and other semiconductor surfaces (Uematsu et al., 2016). As such, one cannot rule out the possibility of adsorption of the hydroquinone derivatives on the surface of $\mathrm{TiO}_{2}$ as a plausible explanation for the loss in photocurrent and low recombination resistance. This can increase the recombination of electrons from the $\mathrm{TiO}_{2}$ conduction band to the quinones, while diminishing the injected photocurrent rate.

Indeed, the electron injection rate is governed by the difference in $R_{r}$ and $R_{t}$ which enables a low enough resistance to the transport of electrons in the $\mathrm{TiO}_{2}$ and a high resistance toward recombination, particularly when $R_{t}$ is about $10^{2}$ orders of magnitude lower than $R_{r}$ in a larger range of voltage. For the cobalt electrolyte, this behavior is seen, and it renders characteristic photovoltaic parameters as opposed to those found for the organic mediators. In terms of the effect of substituents on the organic mediators, DTHQ/DTBQ exhibits the larger difference between $R_{r}$ and $R_{t}$ (Figs. 7 and S7 in Supporting Info), which agrees with higher efficiency (Table 1 ).

In addition, the derivatives DTHQ and ThymHQ achieved lower transport resistances than HQ, which can be ascribed to faster electron transport in the semiconductor layer and faster injection of electrons to the external circuit; these derivatives feature better performances and conversion efficiencies. 
Table 3

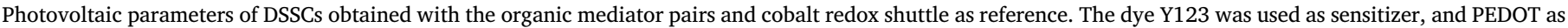
catalyst in the CE.

\begin{tabular}{|c|c|c|c|c|c|}
\hline Redox pair & $\mathrm{V}_{\mathrm{OC}}(\mathrm{mV})$ & $\mathrm{J}_{\mathrm{SC}}\left(\mathrm{mA} \mathrm{cm}^{-2}\right)$ & $\mathrm{W}_{\max }\left(\mathrm{mW} \mathrm{cm}^{-2}\right)$ & $\mathrm{FF}$ & (\%) \\
\hline $\mathrm{Co}^{2+} \beta^{3+}$ & $879 \pm 8$ & $14.4 \pm 0.4$ & $8.6 \pm 0.3$ & $0.68 \pm 0.01$ & $8.6 \pm 0.2$ \\
\hline HQ/BQ & $533 \pm 8$ & $6.5 \pm 0.5$ & $1.05 \pm 0.04$ & $0.30 \pm 0.01$ & $1.08 \pm 0.04$ \\
\hline PhHQ/PhBQ & $528 \pm 37$ & $6.3 \pm 0.8$ & $1.3 \pm 0.3$ & $0.39 \pm 0.01$ & $1.3 \pm 0.1$ \\
\hline DTHQ/DTBQ & $542 \pm 3$ & $12.6 \pm 0.6$ & $2.5 \pm 0.4$ & $0.36 \pm 0.04$ & $2.5 \pm 0.4$ \\
\hline ThymHQ/ThymBQ & $455 \pm 61$ & $10 \pm 2$ & $2.0 \pm 0.6$ & $0.44 \pm 0.01$ & $2.0 \pm 0.7$ \\
\hline
\end{tabular}

$\mathrm{J}-\mathrm{V}$ data represents the mean of two devices each, with standard deviation.

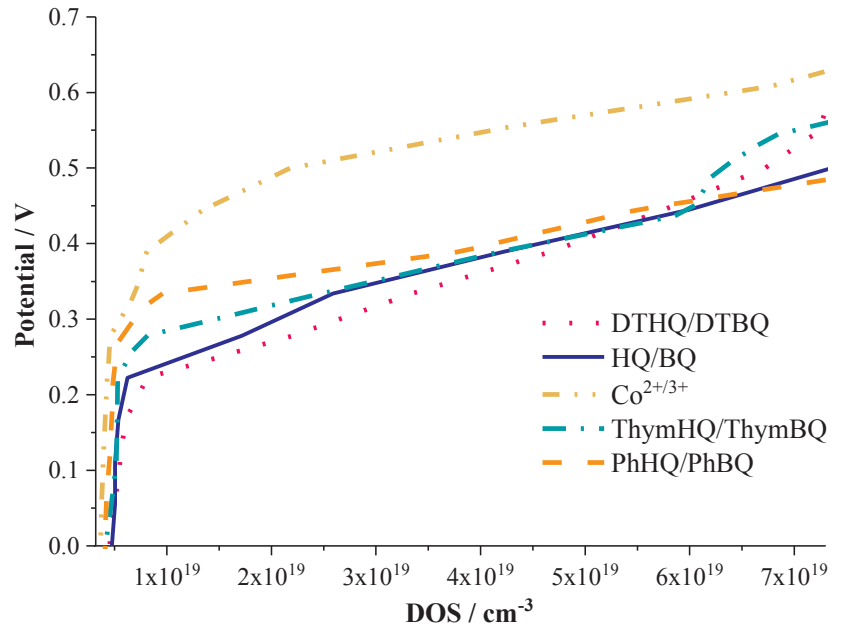

Fig. 6. Corrected potential versus density of states (DOS) under dark conditions, DOS for DSSCs with Y123 dye in the range of medium to high potentials for the organic electrolytes (278-611 mV).

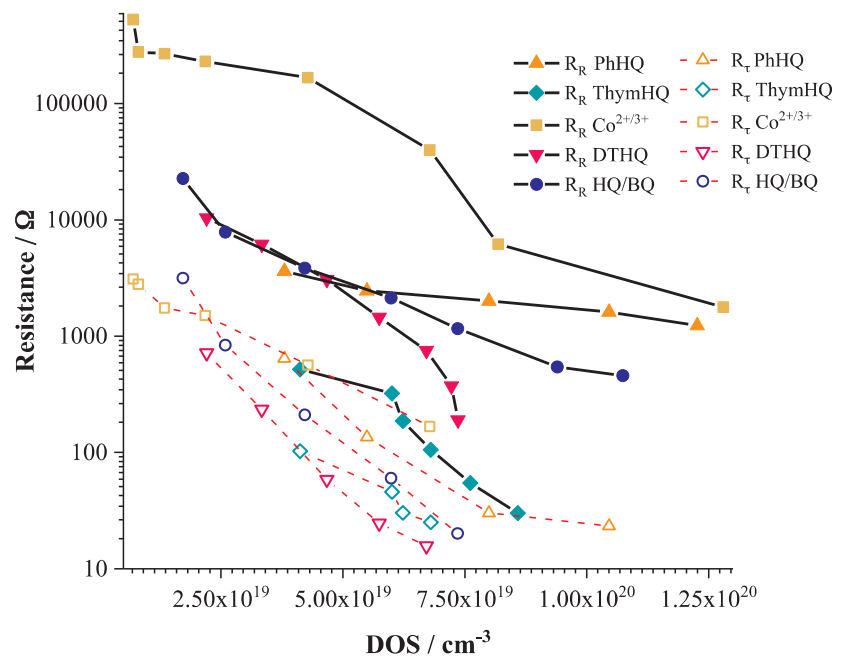

Fig. 7. Recombination resistance $\left(R_{r}\right)$ and transport resistance $\left(R_{t}\right)$ versus DOS for DSSCs with Y123 dye using the organic mediator pairs. DOS are the equivalent to the range of medium to high potentials for the organic electrolytes. Measurements were performed under dark conditions.

As the photovoltaic performance of DTHQ and ThymHQ revealed higher short-circuit currents, they were further tested with another efficient organic sensitizer (LEG4). The photovoltaic results are shown in Table 4, and the corresponding J-V curves are displayed in Fig. 8. The obtained short-circuit currents compare well with cobalt and copperbased electrolytes $\left(11.00 \mathrm{~mA} \mathrm{~cm}^{-2}\right.$ and $12.07 \mathrm{~mA} \mathrm{~cm}^{-2}$, respectively) (Freitag et al., 2016), and with ruthenium-based sensitizers (12.17 $\mathrm{mA} \mathrm{cm}^{-2}-13.89 \mathrm{~mA} \mathrm{~cm}^{-2}$ ) also with cobalt electrolytes (Zhang et al., 2016). Again, low $\mathrm{V}_{\mathrm{OC}}$ and fill factor values had a detrimental effect in the conversion efficiencies with LEG4.

Interestingly, the use of a hybrid counter electrode with PEDOT and graphene brings about an improvement in their photovoltaic parameters and might involve a favorable mechanism in the redox reaction/ charge transfer (Fig. 8). As such, the combination of ThymHQ/ThymBQ with LEG4 and hybrid CE with PEDOT and graphene (regardless of the light intensity) yields the highest conversion efficiencies (3.34\% under $12.3 \%$ sun, $3.29 \%$ under $51.8 \%$ sun and $3.19 \%$ efficiency under $98 \%$ sun).

Photocurrent-dynamics as a function of light intensity for DSSCs with Y123 dye and all the organic redox pairs as mediators were also measured (Figs. S9-S13 in Supporting Info). The results for cobalt as reference and the ThymHQ/ThymBQ derivative are shown in Figs. S9 and S10 in Supporting Info. Regardless of the organic redox pairs, comparing the photocurrent data of ThymHQ/ThymBQ with that of $\mathrm{Co}^{2+/ 3+}$, current dynamics gave the same behavior; seemingly there are no diffusion limitations as the photogenerated current at all light intensities remains constant for each time pulse, which is in agreement with the obtained values for diffusion coefficients of the organic mediators (Table 2). This behavior can be attributed to the small size of the hydroquinone derivatives compared with bulky cobalt complexes, which do have diffusion limitations, slowing the rates of dye regeneration. This characteristic also indicates that diffusion of the organic species in the electrolyte is not an issue for the current loss and limitation of photovoltages observed for the organic mediators; in fact, it seems they have good diffusion rates that could promote the process of regeneration of the oxidized dye molecules.

\section{Conclusions}

In summary, the facile synthesis and photovoltaic performance of organic mediator couples based on hydroquinone/benzoquinone derivatives as redox mediators in DSSCs were demonstrated. DTHQ and ThymHQ feature high values of $\mathrm{J}_{\mathrm{SC}}$ and can be useful if further molecular designs are proposed to improve mainly FF and $\mathrm{V}_{\mathrm{OC}}$.

Moreover, the derivatives DTHQ, ThymHQ, and PhHQ with their quinone counterparts as redox mediators highlight how, by fine-tuning the steric hindrance of bulky substituents, the performance is enhanced relative to unsubstituted HQ/BQ. ThymHQ/ThymBQ with LEG4 dye and a hybrid counterelectrode (PEDOT and graphene) are highly versatile under different light intensities, and yield the highest conversion efficiencies among the different derivatives.

Importantly, the loss in photocurrent and low FF values can be explained by low recombination resistances, as suggested by the EIS analysis. As well, the recombination losses can be rationalized by adsorption of the quinones on the semiconductor, unfavorable interactions of the additives (TBP) with the redox species, and the dynamics of a possible mechanism that enables recombination over regeneration of the dyes. Our investigation will be continued in the future to examine the effect of the kinetics on the efficiency, the changes in the additives on the electrolytes, and especially the synthesis of quinone derivatives bearing electron-donating groups on the overall DSSC performance. 
Table 4

Photovoltaic parameters of DSSCs obtained with the organic mediator pairs. The dye LEG4 was used as the sensitizer, and PEDOT or PEDOT + graphene as the catalysts in the CE.

\begin{tabular}{|c|c|c|c|c|c|c|}
\hline Redox pair & Dye & $\mathrm{V}_{\mathrm{OC}}(\mathrm{mV})$ & $\mathrm{J}_{\mathrm{SC}}\left(\mathrm{mA} \mathrm{cm}{ }^{2}\right)$ & $\mathrm{W}_{\max }\left(\mathrm{mW} \mathrm{c \textrm {cm } ^ { 2 } )}\right.$ & $\mathrm{FF}$ & $\eta(\%)$ \\
\hline DTHQ/DTBQ & LEG4 & $524 \pm 3$ & $12 \pm 2$ & $1.3 \pm 0.3$ & $0.29 \pm 0.05$ & $1.3 \pm 0.3$ \\
\hline ThymHQ/ThymBQ & LEG4 & $510 \pm 18$ & $12.02 \pm 0.08$ & $2.7 \pm 0.2$ & $0.44 \pm 0.04$ & 2.70 .2 \\
\hline DTHQ/DTBQ $^{\mathrm{a}}$ & LEG4 & $474 \pm 51$ & $13.4 \pm 0.3$ & $2.63 \pm 0.06$ & $0.42 \pm 0.04$ & $2.69 \pm 0.05$ \\
\hline ThymHQ/ThymBQ ${ }^{\mathrm{a}}$ & LEG4 & $510 \pm 5$ & $12.3 \pm 0.4$ & $2.9 \pm 0.3$ & $0.47 \pm 0.02$ & $3.19 \pm 0.3$ \\
\hline
\end{tabular}

$\mathrm{J}-\mathrm{V}$ data represents the mean of two devices each, with standard deviation.

a Cells using CE with PEDOT + graphene.

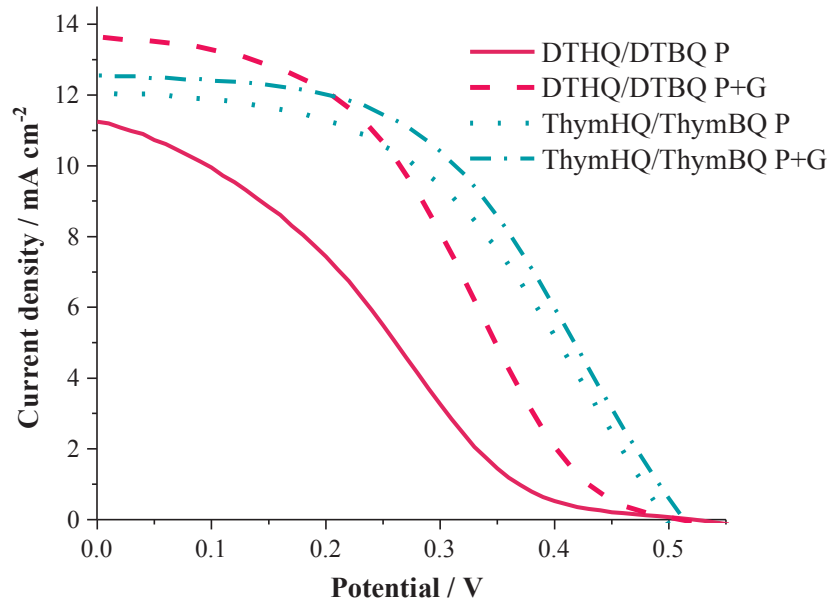

Fig. 8. J-V curves for DSSCs with organic electrolytes using derivatives ThymHQ and DTHQ sensitized with LEG4 and PEDOT as CE (dashed lines) and hybrid CE with PEDOT and graphene (solid lines).

\section{Acknowledgements}

The authors are thankful to Centro de Electroquímica y Energía Química (CELEQ), Centro de Investigación en Productos Naturales (CIPRONA), and Vicerrectoría de Investigación, Universidad de Costa Rica (project number 804-B5-271) for financial support. N. F. greatly acknowledges an Orlando Bravo scholarship for master degree by CELEQ, Sistema de Estudios de Posgrado (SEP), Universidad de Costa Rica, and Prof. Anders Hagfeldt, for a research stay at École Polytechnique Fédérale de Lausanne (EPFL), Switzerland.

\section{Appendix A. Supplementary material}

Supplementary data associated with this article can be found, in the online version, at http://dx.doi.org/10.1016/j.solener.2018.03.084.

\section{References}

Aghazada, S., Gao, P., Yella, A., Marotta, G., Moehl, T., Teuscher, J., Moser, J.-E.E., De Angelis, F., Grätzel, M., Nazeeruddin, M.K., 2016. Ligand engineering for the efficient dye-sensitized solar cells with ruthenium sensitizers and cobalt electrolytes. Inorg. Chem. 55, 6653-6659. http://dx.doi.org/10.1021/acs.inorgchem.6b00842.

Alligrant, T.M., Hackett, J.C., Alvarez, J.C., 2010. Acid/base and hydrogen bonding effects on the proton-coupled electron transfer of quinones and hydroquinones in acetonitrile: Mechanistic investigation by voltammetry, ${ }^{1} \mathrm{H}$ NMR and computation. Electrochim. Acta 55, 6507-6516. http://dx.doi.org/10.1016/j.electacta.2010.06. 029.

Astudillo, P.D., Tiburcio, J., González, F.J., 2007. The role of acids and bases on the electrochemical oxidation of hydroquinone: Hydrogen bonding interactions in acetonitrile. J. Electroanal. Chem. 604, 57-64. http://dx.doi.org/10.1016/j.jelechem. 2007.02.031.

Bella, F., Galliano, S., Gerbaldi, C., Viscardi, G., 2016. Cobalt-based electrolytes for dyesensitized solar cells: recent advances towards stable devices. Energies 9, 384. http:// dx.doi.org/10.3390/en9050384.

Bella, F., Galliano, S., Falco, M., Viscardi, G., Barolo, C., Grätzel, M., Gerbaldi, C., 2017. Approaching truly sustainable solar cells by the use of water and cellulose derivatives. Green Chem. http://dx.doi.org/10.1039/C6GC02625G.
Bhat, M.A., 2012. Mechanistic, kinetic and electroanalytical aspects of quinone-hydroquinone redox system in $\mathrm{N}$-alkylimidazolium based room temperature ionic liquids. Electrochim. Acta 81, 275-282. http://dx.doi.org/10.1016/j.electacta.2012.07.059.

Bisquert, J., Grätzel, M., Wang, Q., Fabregat-Santiago, F., 2006. Three-channel transmission line impedance model for mesoscopic oxide electrodes functionalized with a conductive coating. J. Phys. Chem. B 110, 11284-11290. http://dx.doi.org/10.1021/ jp0611727.

Boschloo, G., Hagfeldt, A., 2009. Characteristics of the iodide/triiodide redox mediator in dye-sensitized solar cells. Acc. Chem. Res. 42, 1819-1826. http://dx.doi.org/10. 1021/ar900138m.

Cheng, M., Yang, X., Zhang, F., Zhao, J., Sun, L., 2012. Efficient dye-sensitized solar cells based on hydroquinone/benzoquinone as a bioinspired redox couple. Angew. Chem. Int. Ed. Engl. 51, 9896-9899. http://dx.doi.org/10.1002/anie.201205529.

Cheng, M., Yang, X.C., Chen, C., Zhao, J.H., Zhang, F.G., Sun, L.C., 2013. Dye-sensitized solar cells based on hydroquinone/benzoquinone as bio-inspired redox couple with different counter electrodes. Phys. Chem. Chem. Phys. 15, 15146-15152. http://dx. doi.org/10.1039/c3cp51980e.

Ellis, H., Eriksson, S.K., Feldt, S.M., Gabrielsson, E., Lohse, P.W., Lindblad, R., Sun, L., Rensmo, H., Boschloo, G., Hagfeldt, A., 2013. Linker unit modification of triphenylamine-based organic dyes for efficient cobalt mediated dye-sensitized solar cells. J. Phys. Chem. C 117, 21029-21036. http://dx.doi.org/10.1021/jp403619c.

Feldt, S.M., Gibson, E.A., Gabrielsson, E., Sun, L., Boschloo, G., Hagfeldt, A., 2010. Design of organic dyes and cobalt polypyridine redox mediators for high-efficiency dyesensitized solar cells. J. Am. Chem. Soc. 132, 16714-16724. http://dx.doi.org/10. 1021/ja1088869.

Freitag, M., Giordano, F., Yang, W., Pazoki, M., Hao, Y., Zietz, B., Grätzel, M., Hagfeldt, A., Boschloo, G., 2016. Copper phenanthroline as a fast and high-performance redox mediator for dye-sensitized solar cells. J. Phys. Chem. C 120, 9595-9603. http://dx. doi.org/10.1021/acs.jpcc.6b01658.

Gamboa-Valero, N., Astudillo, P.D., González-Fuentes, M.A., Leyva, M.A., Rosales-Hoz, M.D.J., González, F.J., 2016. Hydrogen bonding complexes in the quinone-hydroquinone system and the transition to a reversible two-electron transfer mechanism. Electrochim. Acta 188, 602-610. http://dx.doi.org/10.1016/j.electacta.2015.12. 060 .

Girault, H.H., 2005. Analytical and Physical Electrochemistry. TrAC Trends in Analytical Chemistry, first ed. EPFL Press, Lausanne. http://dx.doi.org/10.1016/j.trac.2005.07. 002.

Guin, P.S., Das, S., Mandal, P.C., 2011. Electrochemical reduction of quinones in different media: a review. Int. J. Electrochem. 2011, 1-22. http://dx.doi.org/10.4061/2011/ 816202.

Gupta, N., Linschitz, H., 1997. Hydrogen-bonding and protonation effects in electrochemistry of quinones in aprotic solvents. J. Am. Chem. Soc. 119, 6384-6391. http:// dx.doi.org/10.1021/ja970028j.

Ito, S., Liska, P., Comte, P., Charvet, R., Péchy, P., Bach, U., Schmidt-Mende, L. Zakeeruddin, S.M., Kay, A., Nazeeruddin, M.K., Grätzel, M., 2005. Control of dark current in photoelectrochemical $\left.\left(\mathrm{TiO}_{2} / \mathrm{I}^{-}-\mathrm{I}_{3}{ }^{-}\right)\right)$and dye-sensitized solar cells. Chem. Commun. (Camb) 4351-4353. http://dx.doi.org/10.1039/b505718c.

Kalyanasundaram, K., Hagfeldt, A., Boschloo, G., Sun, L., Kloo, L., Pettersson, H., 2010. Dye-sensitized solar cells. Chem. Rev. 110, 6595-6663. http://dx.doi.org/10.1021/ cr900356p.

Monge-Romero, I.C., Suárez-Herrera, M.F., 2013. Electrocatalysis of the hydroquinone/ benzoquinone redox couple at platinum electrodes covered by a thin film of poly(3,4ethylenedioxythiophene). Synth. Met. 175, 36-41. http://dx.doi.org/10.1016/j. synthmet.2013.04.027.

Nair, J.R., Porcarelli, L., Bella, F., Gerbaldi, C., 2015. Newly elaborated multipurpose polymer electrolyte encompassing RTILs for smart energy-efficient devices. ACS Appl. Mater. Interfaces 7, 12961-12971. http://dx.doi.org/10.1021/acsami. 5b02729.

O'Reagan, B., Grätzel, M., 1991. A low-cost, high-efficiency solar cell based on dye-sensitized colloidal $\mathrm{TiO}_{2}$ films. Nature 353, 737-740. http://dx.doi.org/10.1038/ $353737 \mathrm{a} 0$.

Park, B.W., Pazoki, M., Aitola, K., Jeong, S., Johansson, E.M.J., Hagfeldt, A., Boschloo, G., 2014. Understanding interfacial charge transfer between metallic PEDOT counter electrodes and a cobalt redox shuttle in dye-sensitized solar cells. ACS Appl. Mater. Interfaces 6, 2074-2079. http://dx.doi.org/10.1021/am405108d.

Pavlishchuk, V.V., Addison, A.W., 2000. Conversion constants for redox potentials measured versus different reference electrodes in acetonitrile solutions at $25^{\circ} \mathrm{C}$. Inorg. Chim. Acta 298, 97-102. http://dx.doi.org/10.1016/S0020-1693(99)00407-7.

Safdari, M., Lohse, P.W., Häggman, L., Frykstrand, S., Högberg, D., Rutland, M., Álvarez, R., Gardner, J., Kloo, L., Hagfeldt, A., Boschloo, G., 2016. Investigation of cobalt 
redox mediators and effects of $\mathrm{TiO}_{2}$ film topology in dye-sensitized solar cells. RSC Adv. 6, 56580-56588. http://dx.doi.org/10.1039/C6RA07107D.

Shaidarova, L.G., Gedmina, A.V., Budnikov, G.K., 2003. Voltammetry of a benzoquinonehydroquinone redox couple at electrodes modified with a polyvinylpyridine film doped with cobalt phthalocyanine. J. Anal. Chem. 58, 171-175. http://dx.doi.org/ 10.1023/A:1022366307246.

Shanti, R., Bella, F., Salim, Y.S., Chee, S.Y., Ramesh, S., Ramesh, K., 2016. Poly(methyl methacrylate-co-butyl acrylate-co-acrylic acid): physico-chemical characterization and targeted dye sensitized solar cell application. Mater. Des. 108, 560-569. http:// dx.doi.org/10.1016/j.matdes.2016.07.021.

Staley, P.A., Newell, C.M., Pullman, D.P., Smith, D.K., 2014. The effect of glassy carbon surface oxides in non-aqueous voltammetry: The case of quinones in acetonitrile. Anal. Chem. 86, 10917-10924. http://dx.doi.org/10.1021/ac503176d.

Sun, Z., Liang, M., Chen, J., 2015. Kinetics of iodine-free redox shuttles in dye-sensitized solar cells: interfacial recombination and dye regeneration. Acc. Chem. Res. 48, 1541-1550. http://dx.doi.org/10.1021/ar500337g.

Teuscher, J., Marchioro, A., Andrès, J., Roch, L.M., Xu, M., Zakeeruddin, S.M., Wang, P., Grätzel, M., Moser, J.E., 2014. Kinetics of the regeneration by iodide of dye sensitizers adsorbed on mesoporous Titania. J. Phys. Chem. C 118, 17108-17115. http:// dx.doi.org/10.1021/jp501481c.

Tsao, H.N., Burschka, J., Yi, C., Kessler, F., Nazeeruddin, M.K., Grätzel, M., 2011. Influence of the interfacial charge-transfer resistance at the counter electrode in dyesensitized solar cells employing cobalt redox shuttles. Energy Environ. Sci. 4, 4921. http://dx.doi.org/10.1039/c1ee02389f.

Uchimiya, M., Stone, A.T., 2009. Reversible redox chemistry of quinones: Impact on biogeochemical cycles. Chemosphere 77, 451-458. http://dx.doi.org/10.1016/j. chemosphere.2009.07.025.

Uematsu, T., Shimomura, E., Torimoto, T., Kuwabata, S., 2016. Evaluation of surface ligands on semiconductor nanoparticle surfaces using electron transfer to redox species. J. Phys. Chem. C. http://dx.doi.org/10.1021/acs.jpcc.5b12698. acs.jpcc.
$5 \mathrm{~b} 12698$.

Wang, J.J., Xie, H., Jin, B.K., 2013. Investigation on electrochemical redox of hydroquinone-fourier transform infrared spectroelectrochemistry techniques. Fenxi Huaxue/ Chinese J. Anal. Chem. 41, 1006-1012. http://dx.doi.org/10.1016/S18722040(13)60667-2.

Wang, M., Chamberland, N., Breau, L., Moser, J.-E., Humphry-Baker, R., Marsan, B., Zakeeruddin, S.M., Grätzel, M., 2010. An organic redox electrolyte to rival triiodide/ iodide in dye-sensitized solar cells. Nat. Chem. 2, 385-389. http://dx.doi.org/10. 1038/nchem.610.

Wu, K.-L., Huckaba, A.J., Clifford, J.N., Yang, Y.-W., Yella, A., Palomares, E., Grätzel, M. Chi, Y., Nazeeruddin, M.K., 2016. Molecularly engineered Ru(II) sensitizers compatible with cobalt(II/III) redox mediators for dye-sensitized solar cells. Inorg. Chem. 55, 7388-7395. http://dx.doi.org/10.1021/acs.inorgchem.6b00427.

Yu, Z., Bu, C., Zhou, Z., Liu, Y., Huang, N., Bai, S., Fu, H., Guo, S., Zhao, X., 2013. Effect of HAc treatment on an open-environment prepared organic redox couple based on hydroquinone/benzoquinone and its application in dye-sensitized solar cells. Electrochim. Acta 107, 695-700. http://dx.doi.org/10.1016/j.electacta.2013.06. 125.

Yum, J.-H., Baranoff, E., Kessler, F., Moehl, T., Ahmad, S., Bessho, T., Marchioro, A., Ghadiri, E., Moser, J.-E., Yi, C., Nazeeruddin, M.K., Grätzel, M., 2012. A cobalt complex redox shuttle for dye-sensitized solar cells with high open-circuit potentials. Nat. Commun. 3, 631. http://dx.doi.org/10.1038/ncomms1655.

Zhang, X., Xu, Y., Giordano, F., Schreier, M.R., Pellet, N., Hu, Y., Yi, C., Robertson, N., Hua, J., Zakeeruddin, S.M., Tian, H., Grätzel, M., 2016. Molecular engineering of potent sensitizers for very efficient light harvesting in thin film solid state dye sensitized solar cells. J. Am. Chem. Soc. 138, 10742-10745. http://dx.doi.org/10.1021/ jacs.6b05281.

Zhu, X.Q., Wang, C.H., Liang, H., 2010. Scales of oxidation potentials, pKa, and BDE of various hydroquinones and catechols in DMSO. J. Org. Chem. 75, 7240-7257. http:// dx.doi.org/10.1021/jo101455m. 